\title{
Wearable technology and health: A bibliometric analysis
}

\section{using SciMAT [version 1; peer review: 1 approved with}

\section{reservations, 1 not approved]}

\section{Marlon Felipe Burbano-Fernandez (iD), Gustavo Ramirez-Gonzalez (iD)}

Telematic Engineering Department, Telematic Engineering Research Group (GIT), University of Cauca, Popayan, Cauca, 190002, Colombia

\author{
V1 First published: $04 \operatorname{Dec} 2018,7: 1893$ \\ https://doi.org/10.12688/f1000research.15622.1 \\ Latest published: $04 \mathrm{Dec}$ 2018, 7:1893 \\ https://doi.org/10.12688/f1000research.15622.1
}

\section{Abstract}

Background: To begin research with cross-thematic topics, an analysis is necessary that collects data and historical accounts about these topics. In the field of health and technology, this principle is not unknown. In this case, it is the interest of this investigation to inquire about the topics "wearable" and "health" in order to gather enough information to establish how it has been developed, what the current topics are and what areas it is planned to study in a near future. The purpose of this study is to analyse the growth of the wearable technology and health subject matter. This will create an account of the most relevant themes over time in this subject and their evolution. This study will have an emphasis on recent years, in order to see which themes may be important for future research and publications. Methods: This paper aims at making a bibliometric exploration using information from the Scopus database using the search chain "weareable AND health" within the years of 2000 to 2017. The bibliometric software SciMAT was used for data visualization and analysis.

Results: The results obtained are an analysis of the growth rate that is presented in Scopus publications between 2000 and 2017. In addition, a bibliometric analysis is obtained through the SciMat software, which shows the relevant issues that arise through time and that may be relevant for future research.

Conclusions: Publications associated with the search chain "Wearable AND Health" from 2000 to 2017 were generally in constant growth over the years. With the SciMAT software, the main theme that was found was that of monitoring systems. In addition, it shows how new themes that are highly relevant emerge, such as mobile technologies and the study of algorithms, which emerge as an evolution from signal processing.

Keywords

Wearable, Health, SciMAT, Scopus

\section{Open Peer Review \\ Approval Status ? X \\ 12 \\ version 1 \\ 04 Dec 2018

$\begin{array}{cc}? & \mathrm{X} \\ \text { view } & \text { view }\end{array}$ \\ 1. Peter Kokol ID, University of Maribor, Maribor, Slovenia \\ 2. Manuel Jesus Cobo ID, University of Cádiz, Cádiz, Spain}

Any reports and responses or comments on the article can be found at the end of the article. 
Corresponding authors: Marlon Felipe Burbano-Fernandez (mfburbano@unicauca.edu.co), Gustavo Ramirez-Gonzalez ( gramirez@unicauca.edu.co)

Author roles: Burbano-Fernandez MF: Conceptualization, Investigation, Writing - Original Draft Preparation, Writing - Review \& Editing; Ramirez-Gonzalez G: Conceptualization, Methodology, Supervision, Writing - Review \& Editing

Competing interests: No competing interests were disclosed.

Grant information: The author(s) declared that no grants were involved in supporting this work.

Copyright: ๑ 2018 Burbano-Fernandez MF and Ramirez-Gonzalez G. This is an open access article distributed under the terms of the Creative Commons Attribution License, which permits unrestricted use, distribution, and reproduction in any medium, provided the original work is properly cited. Data associated with the article are available under the terms of the Creative Commons Zero "No rights reserved" data waiver (CCO 1.0 Public domain dedication).

How to cite this article: Burbano-Fernandez MF and Ramirez-Gonzalez G. Wearable technology and health: A bibliometric analysis using SciMAT [version 1; peer review: 1 approved with reservations, 1 not approved] F1000Research 2018, 7:1893

https://doi.org/10.12688/f1000research.15622.1

First published: 04 Dec 2018, 7:1893 https://doi.org/10.12688/f1000research.15622.1 


\section{Introduction}

Wearable technology, termed wearables, are increasingly becoming an essential part of activity tracking for people. They are part of the Internet of Things (Miorandi et al., 2012) and are characterized by their capability of being worn by the user, who can, at any moment, give or execute commands, even if the user is in movement or performing daily activities (MunozOrganero \& Lotfi, 2016). Vandrico Inc. states that the ideal wearable device must meet the following characteristics: be wearable, i.e. it must be used on the person's body; controllable, i.e. the device must be controlled by the user actively or passively; offer evolution, i.e. the device must provide knowledge, make learning easier or make the experience more enjoyable; mobile, i.e. the device must give the users the freedom to act naturally without being limited to a fixed area.

According to these characteristics, it is logical to think that wearables can be used to take care of health by making it possible for the data to flow between people and health professionals to the point of making monitoring and alerts automatic (Corti, 2016). As an example, diabetes patients have been monitored through wearables as shown in recent (Lee et al., 2016) and former (Shichiri et al., 1986; Meyerhoff et al., 1993) studies. The former studies indicate that the idea of using wearables is not recent. Consequently, it is now time to perform a bibliometric compilation to observe the growth in publications throughout the years on this topic, looking at the geographical location where this topic is mentioned, who are its main authors and the main journals where it has been published, as well as its evolution over time. This will make it possible to have an idea of the topics to be investigated in the near future.

In this study, a bibliometric analysis was performed from data collected from the Scopus database between the years of 2000 and 2017.

\section{Methods}

\section{Scopus data in SciMAT}

The data for this bibliometric study was extracted from the Scoups database, by using the search chain "wearable AND health" and downloading the information of the format .RIS. For the download, it must be done in blocks of 2000 documents (corresponding to the maximum selection in Scopus). Only the aforementioned search chain was used as a search criterion and no documents between the years 2000 and 2017 were discarded. The search was made in June 2018.

The downloaded data were entered into the SciMAT software (SciMAT-v1.1.04), which can be freely downloaded (http://sci2s.ugr. es/scimat/download.html). The data entered can be viewed with the option "Knowledge base $->$ Documents $->$ Document manager". In this case, in the first instance we find that there is a total of 6001 downloaded data. Using the Document manager view, the fields shown in an Excel spreadsheet were copied and pasted (In this case, Microsoft Office 2016 was used), and with the use of the option "Conditional Format" the repeated data were found by title. In these duplicate data by title, the documents that had the oldest year were excluded from the database compiled in
SciMAT. From this search, 5696 documents were found after excluding duplicated documents.

Then, with the SciMAT software, "Group set $->$ Word $->$ Find similar word by plurals (automatic)" was used in order to limit the number of words with the same meaning between plural and singular. Finally, through "Knowledge base $->$ Words $->$ Words manager" were joined words or acronyms that had the same meaning, for example "ML" and "Machine Learning". And others that were irrelevant because they are obvious were eliminated, for example, the word "wearble" and "health" is removed from the database.

The adapted database can be found in the file attached to this document. To enter, you must have SciMAT installed, and through the "File $->$ Open Project" option, access the "AnalysisScimat" file.

\section{Analysis using SciMAT}

This data was visualized with the software SciMAT, using a filtering process to avoid duplicity in similar documents and words. A growth analysis was done to see the number of articles published per year. Finally, SciMAT's analysis tool was used to make connections between different periods and different clusters of relevant topics throughout the years.

From the documents found from Scopus, descriptions were made based on the data classified by the software SciMAT-v1.1.04 on three fundamental aspects: period of time between the years of 2000 and 2017. The journals where they were published; the authors who published under the topics of "wearable AND health".

The SciMAT software was used for the bibliometric analysis in accordance to the indications of Cobo et al. (2012). The process has three modules. 'Module to manage the knowledge base'. 'Module to carry out the science mapping analysis'. And 'Visualization module'. In the 'Module to manage the knowledge base' build the know base, importing files .ris, edited entities, quit duplicated documents and was defined periods. In 'Module to carry out the science mapping analysis', was selected periods, selected unit of analysis selections, data reduction, kind of network, network reduction, normalization, clustering, document mappers, quality measures and longitudinal analysis. Finally, in Visualization module we did visualization and interpretation. Table 1 shows the selected parameters.

\section{Results}

\section{Publications per year}

Table 2 shows four columns. In the first one is the published documents year. The second corresponds to the number of documents found in that year. The third column corresponds to the percentage of articles corresponding to each year. Finally, in the fourth column, you can find the growth rate of the previous year (the difference between the publications made in a year subtracted from the previous year). It can be observed there are two periods when there is decrease in the production of articles on the subject of wearables and health. In 2001, there were 3 less articles 
Table 1. Selected parameters in SciMAT

\begin{tabular}{|c|c|}
\hline & Module to manage the knowledge base \\
\hline Build knowledge base & SCOPUS \\
\hline Import files & ris \\
\hline \multicolumn{2}{|l|}{ Entities edition } \\
\hline De duplicating & $\begin{array}{l}\text { Use word SciMAT word manager. } \\
\text { Manual union of similar or duplicate words. } \\
\text { Manual duplicated documments search }\end{array}$ \\
\hline Period definition & 2000-2005, 2006-2010, 2011, 2012, 2013, 2014, 2015, 2016, 2017 \\
\hline \multicolumn{2}{|r|}{ Module to carry out the science mapping analysis } \\
\hline Period selection & 2000-2005, 2006-2010, 2011, 2012, 2013, 2014, 2015, 2016, 2017 \\
\hline Unit of analysis selection & Words: Author's words, Source's words, Added words \\
\hline Data reduction & Minimum frequency for all periods: 4 \\
\hline Kind of network & Co-occurrence \\
\hline Network reduction & Minimum value: 4 \\
\hline Normalization & Equivalence index \\
\hline Clustering & Maximum network size: 8 Minimum network size: 5 \\
\hline Document mapper & Core mapper Secondary mapper \\
\hline Quality measures & h-index Sum citation \\
\hline Longitudinal analysis & Evolution map: Jaccard's index Overlapping map: Inclusion index \\
\hline \multicolumn{2}{|r|}{ Visualization module } \\
\hline Visualization & Longitudinal view Period view \\
\hline
\end{tabular}

Table 2. Publications per year and growth rate in the topic wearable technology and health, as found in Scopus 2007-2017.

\begin{tabular}{|c|c|c|c|}
\hline Year & Publications & Percentage & $\begin{array}{c}\text { Growth } \\
\text { rate }\end{array}$ \\
\hline 2017 & 1378 & $24 \%$ & 330 \\
\hline 2016 & 1048 & $18 \%$ & 170 \\
\hline 2015 & 878 & $15 \%$ & 418 \\
\hline 2014 & 460 & $8 \%$ & 100 \\
\hline 2013 & 360 & $6 \%$ & 52 \\
\hline 2012 & 308 & $5 \%$ & 5 \\
\hline 2011 & 303 & $5 \%$ & 93 \\
\hline 2010 & 210 & $4 \%$ & 47 \\
\hline 2009 & 163 & $3 \%$ & -9 \\
\hline 2008 & 172 & $3 \%$ & 49 \\
\hline 2007 & 123 & $2 \%$ & 32 \\
\hline 2006 & 91 & $2 \%$ & 4 \\
\hline 2005 & 87 & $2 \%$ & 42 \\
\hline 2004 & 45 & $1 \%$ & 14 \\
\hline 2003 & 31 & $1 \%$ & 11 \\
\hline 2002 & 20 & $0 \%$ & 12 \\
\hline 2001 & 8 & $0 \%$ & -3 \\
\hline 2000 & 11 & $0 \%$ & 11 \\
\hline Total & 5696 & $100 \%$ & \\
\hline & & & \\
\hline
\end{tabular}

than in 2000; however, that is not relevant considering both years concentrated less than $1 \%$ of the total production of documents in Scopus. Between 2008 and 2009 the production declined by 9 documents, but it is necessary to take into account that in both years the production was $1 \%$ of the total, with 163 documents in 2009 and 172 in 2008. This implies that, even if the production of articles declined in general, this decline was not relevant. Table 1 also shows that the bibliographic production of studies on wearables and health is increasing.

\section{Results}

The graphics generated according to the visualization module are shown in Figure 1-Figure 3. For this study, the evolution map, the strategic map for the periods 2015, 2016 and 2017, and the cluster associated 2017 maps were created (Cobo et al., 2012; Sánchez et al., 2014).

\section{Evolution map}

Figure 1 shows the evolution map. This map shows that in the period of 2000-2005, only two themes were relevant: 'Telemedicine' and 'Bluetooth'. In the period of 2006-2010, the term 'Telemedicine' converges mainly to 'Monitoring system' and the theme 'Bluetooth' converges to 'Mobile technology'. In addition, in this period, new themes appear. In the period of 2011, the themes are reduced to 'Monitoring system' and 'Health care'. In the periods of 2012 and 2013, the theme of 'Monitoring system' is mainly maintained. In 2014, the theme 'Monitoring system' was diversified into 'Device', 'Accelerometer', 'Mobile Technology' and 'Health care'. In the period of 2015, the themes of 'Devices' and 'Mobile Technology' are maintained, and, besides, 


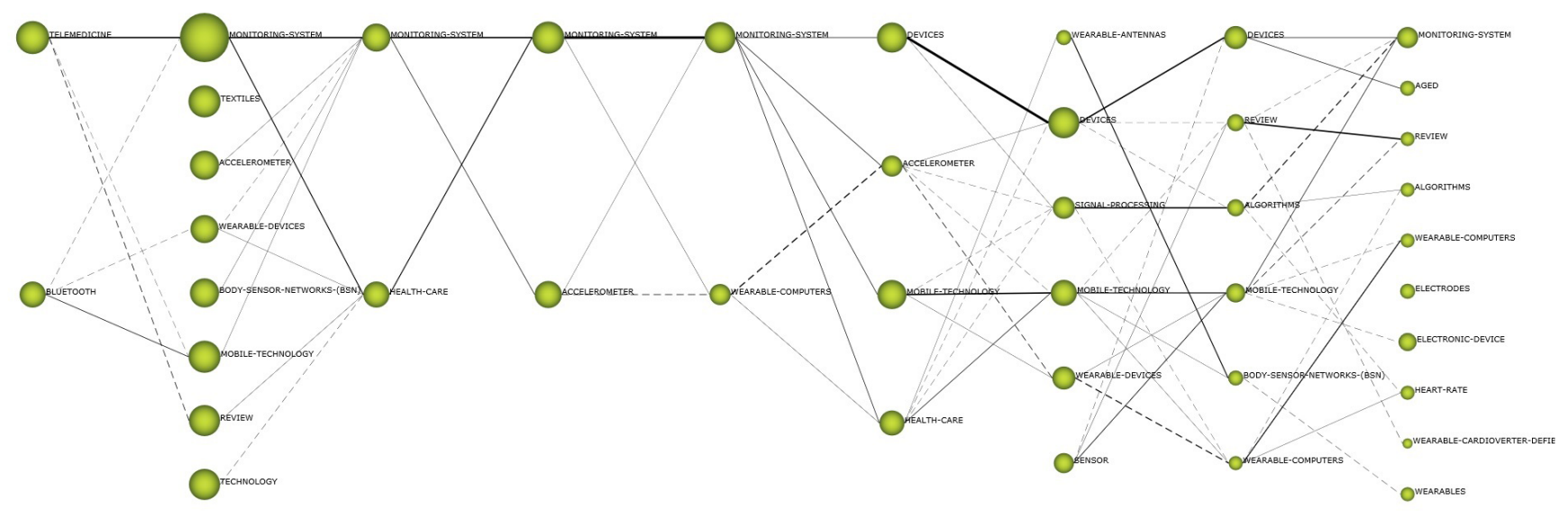

Figure 1. Evolution map of themes from publications on the topic wearable technology and health, as found in Scopus $2007-2017$.

A

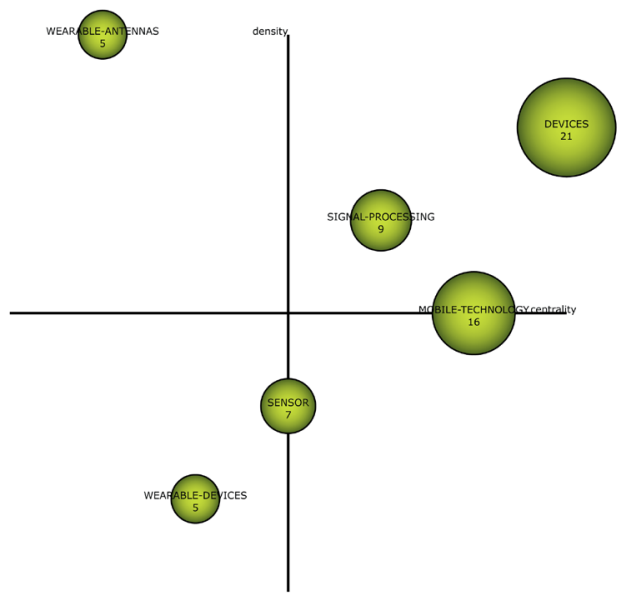

B

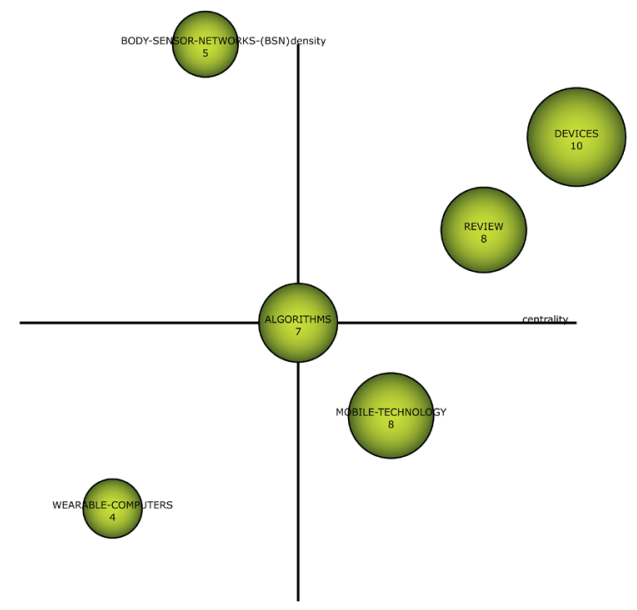

C

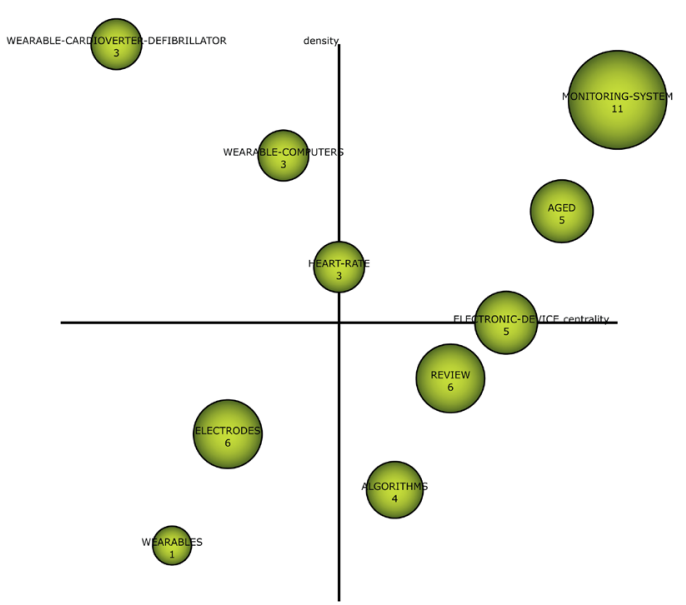

Figure 2. Strategic map of themes from publications on the topic wearable technology and health, as found in Scopus. (A) 2015, (B) 2016 and (C) 2017 
A
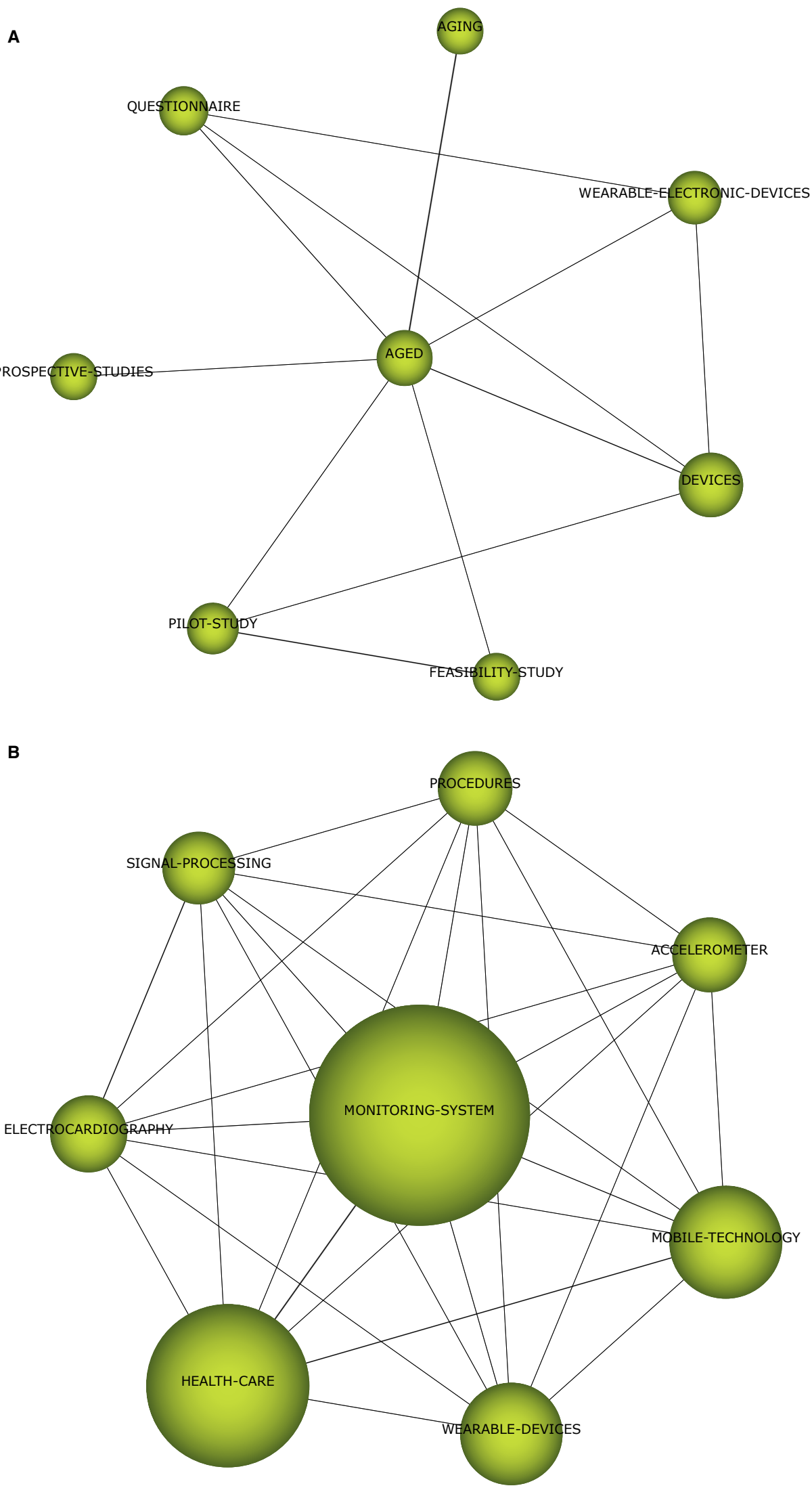

Figure 3. Clusters of themes from publications on the topic wearable technology and health, as found in Scopus 2017. 
the themes of 'wearable antennas', 'Signal processing', 'wearable devices' and 'Sensor' appear. In the period of 2016, the themes 'Devices', 'mobile technology' are maintained; 'signal processing' evolves into the theme of 'Algorithms', while 'Wearable antennas' evolve into 'Body sensor network', and the theme of 'wearable computers' appears. Finally, in 2017, the theme of 'Devices' evolves into 'Monitoring System' and 'Aged'; the themes of 'Wearable computer' and 'Algorithms' are maintained.

It is interesting to observe that, in the evolutionary analysis from 2000 to 2005, the themes were not very diverse. From 2006 to 2010, several themes of interest appear, but in the periods of 2011 to 2014 they again focus on two themes only. In these periods, the predominant theme is 'Monitoring system' and it evolves in the periods of 2015 and 2016 into the 'Devices' theme, and then finally, in the period of 2017, the topics of 'Monitoring system' and 'Aged' are resumed. In the period of 2014, the theme of 'Mobile technology' is resumed, which is maintained until the period of 2016, and in the period of 2017 the theme 'Monitoring system' evolves. In the period of 2015 , the theme of 'Signal processing' becomes stronger, which evolves in the periods of 2016 and 2017 into the theme 'Algorithms'.

\section{Strategic map}

In Figure 2, the Strategic maps for the years 2015, 2016 and 2017 are shown, where the themes that emerge and those that are in motor clusters according to their centrality and their density can be seen. In the period of 2015 it is observed that the topics that in the motor cluster region 'Signal processing' and 'Devices' appear. In the period of 2016, the theme of 'Devices' and 'Review' is mainly in the motor cluster region. In this period, the theme of 'Algorithms' is also at the center. Finally, in the period of 2017, the themes in the motor cluster are 'Monitoring System' and 'Aged'.

\section{Cluster associated}

For this case, the two themes that are found in the motor cluster regions for the period of 2017 were taken into account. In this case, it can be observed that the theme of 'Monitoring system' is related to themes that present potential for studies, such as 'Health care', 'Mobile technology' and 'Wearable devices', among other themes. It can be observed that 'Monitoring system' is the center of the cluster, but that all the other themes are related to each other.

Another theme that is found in the motor cluster region is the theme of 'Aged', which is the center of the graph. For this case, its related topics are focused on pilot studies, of prospective and feasibility. Other themes related to this theme are 'Devices' and 'Wearable electronic devices'. In this case, it can be observed that 'Aged' is related to the other themes, but these do not relate much to each other.

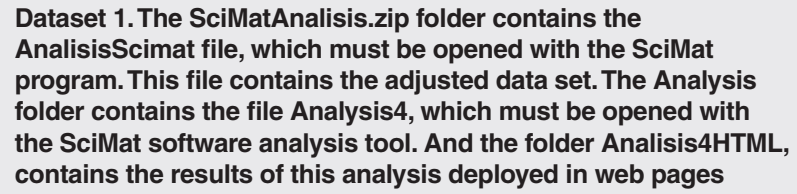

https://dx.doi.org/10.5256/f1000research.15622.d224368

\section{Discussion}

In the evolution diagram performed in this study, it can mainly be observed that the theme that transcends over time is that of monitoring systems, This shows that wearable devices have been thought of as health monitoring systems from the beginning of their development. Between 2016 and 2017, it can be seen that the use of devices in the theme of aged also becomes important. In addition, it can be observed that since 2014 mobile technologies have become very relevant and finally, in 2017 , they evolve into monitoring systems. In any case, it can be seen that wearable devices in the health care area have mainly been used for monitoring systems.

In the strategic maps, what can be found in the evolution diagrams is corroborated, where the rising theme for 2017 is 'Monitoring system', which evolves from the theme 'Devices' in 2015 and 2016. In 2015, it can be observed that a relevant theme was 'Signal processing', which evolves into 'Algorithms' in 2016, but which in 2017 becomes a basic and transversal theme. This implies that, although there are many studies on these themes, future studies in this area may not necessarily have an impact.

Finally, the two most relevant topics found for the cluster diagrams show that monitoring systems are the most relevant for possible studies, where the sub-themes of health care, mobile technology and wearable devices are the most relevant. To a lesser extent, it is interesting that there also are relations to the themes connected to accelerometers, procedures, signal processing and electrocardiography. On the other hand, not so relevant but equally important, it is possible to see that the theme of 'Aged' is important, whereas associated sub-themes are prospective, pilot and feasibility studies for the use of devices and wearables.

\section{Conclusions}

As a first conclusion, it could be observed that in Scopus, publications associated with the search chain "Wearable AND Health" from 2000 to 2017 were generally in constant growth over the years.

In the evolutionary map found with the SciMAT software, it was found that in the studied search chain, the main theme that was found was that of monitoring systems. In addition, it shows how new themes that are highly relevant emerge, such as mobile technologies and the study of algorithms, which emerge as an evolution from signal processing.

In the strategic map for the years of 2015, 2016 and 2017, it is corroborated that the transcendental themes are devices, which evolve into the themes of monitoring system and aged, which may be relevant for future studies.

The cluster diagram for the period of 2017 in the monitoring system and aged themes is shown. In the theme of monitoring system, the themes of health care, mobile technology and wearable device are shown as good proposals for future studies. Similarly, the themes of accelerometer, procedures, signal processing and electrocardiogram can also be good proposals, but to a lesser extent. It should be noted that, according to this diagram, there are combinations between all these themes. In the theme 
of 'Aged', the studies are more focused on prospective, pilot or feasibility studies for the use of devices and wearables, these being good alternatives for future studies.

\section{Data availability}

F1000Research: Dataset 1. The SciMatAnalisis.zip folder contains the AnalisisScimat file, which must be opened with the SciMat program. This file contains the adjusted data set. The Analysis folder contains the file Analysis4, which must be opened with the SciMat software analysis tool. And the folder Analisis4HTML, contains the results of this analysis deployed in web pages, https://doi.org/10.5256/f1000research.15622.d224368 (BurbanoFernandez, 2018).

SciMat software is available from: https://sci2s.ugr.es/scimat/ download.html, under a GPLv3 license.

\section{Grant information}

The author(s) declared that no grants were involved in supporting this work.
Burbano-Fernandez MF, Ramirez-Gonzalez G: Dataset 1 in: Wearable technology and health: A bibliometric analysis using SciMAT. F1000Research. 2018. http://www.doi.org/10.5256/f1000research.15622.d224368

Cobo MJ, López-Herrera AG, Herrera-Viedma E, et al.: SciMAT: A new science mapping analysis software tool. Journal of the Association for Information Science and Technology. 2012; 63(8): 1609-1630.

Publisher Full Text

Corti S: Impacto de dispositivos "wearables" en el monitoreo de la salud. 2016. Reference Source

Lee H, Choi TK, Lee YB, et al:: A graphene-based electrochemical device with thermoresponsive microneedles for diabetes monitoring and therapy. Nat Nanotechnol. 2016; 11(6): 566-572.

PubMed Abstract | Publisher Full Text

Meyerhoff C, Bischof F, Mennel FJ, et al:: On line continuous monitoring of blood lactate in men by a wearable device based upon an enzymatic amperometric lactate sensor. Biosens Bioelectron. 1993; 8(9-10): 409-414. PubMed Abstract | Publisher Full Text
Miorandi D, Sicari S, De Pellegrini F, et al:: Internet of things: Vision, applications and research challenges. Ad Hoc Networks. 2012; 10(7): 1497-1516. Publisher Full Text

Munoz-Organero M, Lotfi A: Human movement recognition based on the stochastic characterisation of acceleration data. Sensors (Basel). 2016; 16(9): pii: E1464.

PubMed Abstract | Publisher Full Text | Free Full Text

Sánchez MÁM, Herrera MD, Fernández AIL, et al:: Un análisis bibliométrico de la producción académica española en la categoría de Trabajo Social del “Journal Citation Report"/A bibliometric analysis of Spanish production of Social Work category according to the Journal Citation Report. Cuadernos de Trabajo Social. 2014; 27(2): 429

Publisher Full Text

Shichiri M, Asakawa N, Yamasaki Y, et al:: Telemetry glucose monitoring device with needle-type glucose sensor: a useful tool for blood glucose monitoring in diabetic individuals. Diabetes Care. 1986; 9(3): 298-301.

PubMed Abstract | Publisher Full Tex 


\section{Open Peer Review}

\section{Current Peer Review Status: ? $\mathrm{X}$}

\section{Version 1}

Reviewer Report 21 December 2018

https://doi.org/10.5256/f1000research.17042.r41646

(C) 2018 Cobo M. This is an open access peer review report distributed under the terms of the Creative Commons Attribution License, which permits unrestricted use, distribution, and reproduction in any medium, provided the original work is properly cited.

\section{Manuel Jesus Cobo}

Department of Computer Science and Engineering, University of Cádiz, Cádiz, Spain

The manuscript presents a bibliometric analysis on wearable health, which is based on co-words networks. To do that, authors employed SciMAT.

In what follows, some comments and suggestion are listed.

- The English is very poor. The authors should make a great effort to improve it, and describe in a clear manner their finding.

I don't understand why there are duplicate documents in the database. There are more than 300 duplicates items, that seems too much. If the authors download the data correctly from Scopus, it is impossible to get duplicates. On the other hand, the number of documents listed in the document manager is equal to the number of records returned by the search?

The methodology seems like a SciMAT tutorial. Authors do not need to describe every single step with the software.

There are two section with the same label.

In the strategic diagram, there are some themes that don't make sense. For instance, Algorithm, review, etc. This broad theme should be marked as stop group in SciMAT, then redo the analysis.

The organization of the results section is strange. First, the authors should describe the periods (each strategic diagram), and then the evolution map.

The references section must be improved. Authors should add citations to the methodology employed, to co-words analysis, bibliographic networks, etc.

Is the work clearly and accurately presented and does it cite the current literature? No

Is the study design appropriate and is the work technically sound? Yes 
Are sufficient details of methods and analysis provided to allow replication by others? Yes

If applicable, is the statistical analysis and its interpretation appropriate? Not applicable

Are all the source data underlying the results available to ensure full reproducibility? Yes

Are the conclusions drawn adequately supported by the results? Yes

Competing Interests: No competing interests were disclosed.

Reviewer Expertise: Bibliometric and science mapping analysis.

I confirm that I have read this submission and believe that I have an appropriate level of expertise to state that I do not consider it to be of an acceptable scientific standard, for reasons outlined above.

Reviewer Report 11 December 2018

https://doi.org/10.5256/f1000research.17042.r41481

(C) 2018 Kokol P. This is an open access peer review report distributed under the terms of the Creative Commons Attribution License, which permits unrestricted use, distribution, and reproduction in any medium, provided the original work is properly cited.

\section{Peter Kokol}

Faculty of Electrical Engineering and Computer Science, University of Maribor, Maribor, Slovenia

The authors performed a bibliometric analysis of the employment of wearable technology in health using the SciMat software. They showed that the literature production is increasing in the period 2000 - 2017. They found that "monitoring systems" is the main research theme. And that new themes like mobile technologies and the study of algorithms are emerging. The paper is interesting and is analysing two topics, which is becoming more and more important and popular.

First, they describe the use of a not so well known bibliometric analysis tool, SciMat. In that respect I would advise that the authors clearly state why they decided to use it, instead of more known tools like VOSViewer. I would also propose that in the discussion they state the advantages and disadvantages of SciMat compared to VOSViewer and other bibliometric tools.

Second, the authors reveals the dynamics of literature production in quite a novel way, and identify most important topics of research. I would suggest that author add the most recent or cited references for each topic they identified. They should also extend the discussion with the implications for practice and further research from the point of maintaining health and 
development of IoT devices. They should also identify the research gaps. Some standard descriptive bibliometric analyses like geographical dispersion of research and most prolific journals, could also be helpful.

Is the work clearly and accurately presented and does it cite the current literature? Partly

Is the study design appropriate and is the work technically sound?

Yes

Are sufficient details of methods and analysis provided to allow replication by others? Yes

If applicable, is the statistical analysis and its interpretation appropriate? Yes

Are all the source data underlying the results available to ensure full reproducibility? Yes

Are the conclusions drawn adequately supported by the results? Yes

Competing Interests: No competing interests were disclosed.

Reviewer Expertise: Software engineering, intelligent systems, bibliometrics, data mining

I confirm that I have read this submission and believe that I have an appropriate level of expertise to confirm that it is of an acceptable scientific standard, however I have significant reservations, as outlined above. 
The benefits of publishing with F1000Research:

- Your article is published within days, with no editorial bias

- You can publish traditional articles, null/negative results, case reports, data notes and more

- The peer review process is transparent and collaborative

- Your article is indexed in PubMed after passing peer review

- Dedicated customer support at every stage

For pre-submission enquiries, contact research@f1000.com 